\title{
Reflections on the Changing Platform of Education for the Budding Otolaryngologist
}

\author{
Betty S. Tsai Do, MD'
}

@SAGE

No sponsorships or competing interests have been disclosed for this article.

\begin{abstract}
Learning is a key component to developing and maintaining competency as a physician. Traditional approaches, such as textbooks, lectures, journal articles, and cadaver laboratories, have been instrumental. With the ease in accessing information, especially via the Internet, this article discusses innovative educational strategies that have evolved from this.
\end{abstract}

\section{Keywords}

web-based learning, team-based learning, social media

Received May 5, 20I5; revised July 6, 20I5; accepted July 27, 2015.

$\mathrm{O}$ ver recent decades, the medical environment learned to embrace technology. The gradual replacement of paper charts, bound journals, and textbooks with electronic medical records, online video lectures, and electronic journals and books shows that the digital age has arrived. Even social media has a footprint in medicine.

Medical education has also changed. Learning time in postgraduate medical training is limited by duty hour regulations. Additionally, physicians are required to participate in the Maintenance of Certification (MOC) program after training completion. How does a student of medicine become a successful physician in this era?

\section{Before Technology}

Previously, learning occurred from slide shows, textbooks, print journals, and library research. Lectures gradually migrated from chalkboards and slides on carousels to PowerPoint presentations. Assigned textbook readings were supplemented by lecture handouts. Preparing for interesting cases and medical student presentations previously required a library trip, as most journals were still not online. Nowadays, online journal access is almost universally available, and many textbooks published today come with online access. Many of these are purchased by libraries for educational institutions, for widespread access.

\section{Web-Based Learning}

Medicine is an ever-changing field, with the information requiring mastery growing exponentially. Yet, time remains limited. Medical schools have started to use web-based learning to enhance clerkship education, allowing students to view the curriculum from anywhere. This has been shown to be more efficient than the traditional classroom in medicine. ${ }^{1}$ A recent survey of medical students and residents showed that $58 \%$ preferred purely electronic resources for learning. ${ }^{2}$ Some residencies have created online curriculums to augment medical and surgical training. ${ }^{3,4}$ Others revamped their didactics by using web-based learning for preparatory reading. In the "flipped classroom" and "teambased learning" approaches, lecture time is then reserved for interactive sessions where learners work together in small groups to tackle problems using knowledge from advance reading assignments, with the faculty member serving as a facilitator. ${ }^{5,6}$ Both approaches require a degree of self-directed learning. This allows each person to focus on his or her own weaknesses, making these programs individually tailored. A recent study at Johns Hopkins University demonstrated that utilizing a learner-centered curriculum improved scores in the otolaryngology training examination. ${ }^{7}$ At our institution, we recently implemented teambased learning and noticed increased resident engagement and interest. Prior to the session, residents have preassigned reading. They all take a prequiz based on the reading and then participate in a group quiz after being divided into 2 teams, in a friendly competition against each other. Within the prediscussion quizzes, individual resident scores improve from as low as $20 \%$ to $30 \%$ to near perfect scores once tackled as a group. This exercise helps to reinforce the concepts from the reading, as those who understand it better explain it to others in the group. Subsequently, these concepts are used to tackle various case studies. Several other residency programs have implemented similar techniques. At Rush University, the Department of General Surgery showed that team-based learning was an effective method in educating residents in systems-based practice - an Accreditation Council for Graduate Medical Education core

\footnotetext{
'Department of Otorhinolaryngology, The University of Oklahoma Health Sciences Center, Oklahoma City, Oklahoma, USA
}

Corresponding Author:

Betty S. Tsai Do, MD, Department of Otorhinolaryngology, The University of Oklahoma Health Sciences Center, 920 Stanton L Young Blvd, WP I290, Oklahoma City, OK 73I04, USA. 
competency. ${ }^{8}$ Prior to the session, $33 \%$ of the residents understood systems-based practice, and $15 \%$ understood its components. At the conclusion of the session, this knowledge improved to $85 \%$ and $89 \%$, respectively. In the era of duty hour limitations, this approach optimizes the few hours that they have.

\section{Keeping Up the Knowledge}

After residency, staying current with the latest medical and surgical innovations becomes more challenging. The patients trust us to be experts in our fields. Our professionalism dictates that we continuously acquire knowledge to practice safe medicine. While that is the intent of the MOC, for some it has become burdensome, especially for subspecialists. How do they keep up, especially if they do not routinely practice other aspects of otolaryngology?

Traditional continuing medical education (CME) found at national conferences requires significant time and finances. Over the years, online CME has become more popular. A recent study showed that younger doctors, $<5$ years out of training, were the highest users of online $\mathrm{CME}$ and more interested in learning the content from online CME as well. ${ }^{9}$ The authors surmised that perhaps the younger doctors' prior exposure to online learning and their familiarity with technology allow them to make the best use of online learning. Even the MOC, which is required for all the younger physicians, has annual self-assessment modules for part II that must be completed entirely online.

\section{Social Media as an Educational Medium}

Younger physicians are also more attuned to social media. Many of us have accounts on Facebook, LinkedIn, Twitter, or Doximity, to name a few. Although social media was intended for individuals to share updates about themselves with friends or followers, medical education programs have taken advantage of the ability to reach out to a large audience to share information. At one institution, physicians in emergency medicine taught students the basics of ultrasonography entirely via Twitter. ${ }^{10}$ Although intended for their own students, with Facebook serving as their discussion board, these physicians quickly found that they acquired an international following of others interested in learning ultrasonography. The use of Twitter and Facebook apps on their mobile devices made the course more accessible for everyone.

\section{Conclusion}

Although traditional forms of learning medicine continue to be useful, alternate forms of education embracing the Internet are gaining popularity. An open attitude toward our education may allow us to learn in ways that will perhaps make us better doctors.

\section{Author Contributions}

Betty S. Tsai Do, full manuscript.

\section{Disclosures}

Competing interests: None.

Sponsorships: None.

Funding source: None.

\section{References}

1. Cook DA, Beckman TJ, Thomas KG, Thompson WG. Adapting web-based instruction to residents' knowledge improves learning efficiency: a randomized controlled trial. $J$ Gen Intern Med. 2008;23:985-990.

2. Egle JP, Smeenge DM, Kassem KM, Mittal VK. The Internet School of Medicine: use of electronic resources by medical trainees and the reliability of those resources. J Surg Educ. 2015;72:316-320.

3. Lebensohn P, Kligler B, Dodds S, et al. Integrative medicine in residency education: developing competency through online curriculum training. J Grad Med Educ. 2012;4:76-82.

4. Maizels M, Mickelson J, Yerkes E, et al. Computer-enhanced visual learning method: a paradigm to teach and document surgical skills. J Grad Med Educ. 2009;1:109-113.

5. Galway LP, Corbett KK, Takaro TK, Tairyan K, Frank E. A novel integration of online and flipped classroom instructional models in public health higher education. BMC Med Educ. 2014; $14: 181$.

6. Michaelsen LK, Parmelee DX, McMahon KK, Levine RE. Team-Based Learning for Health Professions Education. Sterling, VA: Stylus Publishing; 2007.

7. Reh DD, Ahmed A, Li R, Laeeq K, Bhatti NI. A learner-centered educational curriculum improves resident performance on the otolaryngology training examination. Laryngoscope. 2014;124:22622267.

8. Chan EY, Deziel DJ, Orkin BA, Wool NL. Systems-based practice: learning the concepts using a teamwork competition model. Am J Surg. 2015;209:40-44.

9. Sandars J, Walsh K, Homer M. High users of online continuing medical education: a questionnaire survey of choice and approach to learning. Med Teach. 2010;32:83-85.

10. Bahner DP, Adkins E, Patel N, Donley C, Nagel R, Kman NE. How we use social media to supplement a novel curriculum in medical education. Med Teach. 2012;34:439-444. 